\title{
Porous Calcium Phosphate-Poly (Lactic-co-Glycolic) Acid Composite Bone Cement: A Viable Tunable Drug Delivery System
}

\author{
Abhijit Roy ${ }^{a}$, Siddharth Jhunjhunwala ${ }^{a}$, Emily Bayer ${ }^{\text {a }}$, Morgan Fedorchak ${ }^{b}$, Steve R. Little ${ }^{\text {a, b }}$ \\ and Prashant N. Kumta ${ }^{\text {a, b, c, d* }}$ \\ ${ }^{a}$ Department of Bioengineering, University of Pittsburgh, Pittsburgh, PA, 15261, USA. \\ ${ }^{\mathrm{b}}$ Department of Chemical Engineering, University of Pittsburgh, Pittsburgh, PA, 15261, USA. \\ ${ }^{c}$ Mechanical Engineering and Materials Science, University of Pittsburgh, Pittsburgh, PA, \\ 15261, USA. \\ ${ }^{\mathrm{d}}$ Oral Biology, and Center for Craniofacial Regeneration, University of Pittsburgh, Pittsburgh, \\ Pennsylvania 15260, USA. E-mail: pkumta@pitt.edu \\ *: corresponding author
}




\section{ABSTRACT}

Calcium phosphate based cements (CPCs) are frequently used as bone void fillers for non-load bearing segmental bone defects due to their clinically relevant handling characteristics and ability to promote natural bone growth. Macroporous CPC scaffolds with interconnected pores are preferred for their ability to degrade faster and enable accelerated bone regeneration. Herein, a composite CPC scaffold is developed using newly developed resorbable calcium phosphate cement $(\mathrm{ReCaPP})$ formulation containing degradable microspheres of bio-compatible poly (lactic-co-glycolic acid) (PLGA) serving as porogen. The present study is aimed at characterizing the effect of in-vitro degradation of PLGA microspheres on the physical, chemical and structural characteristics of the composite cements. The porosity measurements results reveal the formation of highly interconnected macroporous scaffolds after degradation of PLGA microspheres. The in-vitro characterizations also suggest that the degradation by products of PLGA reduces the $\mathrm{pH}$ of the local environment thereby increasing the dissolution rate of the cement. In addition, the in-vitro vancomycin release from the composite CPC scaffold suggests that drug association with composite scaffolds can be tuned to achieve control release kinetics. Further, the study demonstrates control release lasting for longer than 10 weeks from the composite cements in which vancomycin is encapsulated in PLGA microspheres.

Keywords: Calcium phosphate cement, PLGA, Porogen, Drug delivery, Controlled release 


\section{Introduction}

It is well known that skeletal defects and bone injuries of a certain critical size and larger pose major treatment challenges as the bone tissue fails to spontaneously heal in a reasonable time. Although autologous bone grafting is highly effective[1, 2], there are few limitations: (i) patients are subjected to a second surgical site, which increases morbidity ( $8 \%$ to $10 \%$ ); (ii) there is a greater risk for wound infection and accompanying higher blood loss; and (iii) there is a slower return to normalcy $[1,3]$. In order to overcome these limitations, there has been continuous interest in the use of naturally derived and synthetic bone graft substitutes designed to guide and direct newly formed bone. An ideal bone substitute would impart osteoconductivity and osteoinductivity into the design of the synthetic porous graft material allowing bone regeneration, while being mechanically stable, biocompatible, as well as displaying degradability [4-6].

One such bone substitute is the ubiquitous calcium phosphate based cement (CPC), which is considered to be promising for non-load bearing applications and has generated a plethora of interest over the last two decades [6-8]. One major advantage of CPCs is its ability to form a malleable and moldable paste upon mixing with aqueous based solutions, which can be easily introduced into the injured site to perfectly and completely fit the defect while also setting within a well-defined short period of time at body temperature resulting in a mechanically stable scaffold [6-8]. These CPCs are biocompatible [6-8], promote new bone formation [9, 10], and can be used for delivering different drugs and growth factors [11-13]. Despite these advantages, a major limitation is their slow in-vivo resorption rate, which leads to inadequate bone regeneration [6-8]. To achieve the desired rapid bone regeneration, it is extremely important to 
have CPC scaffolds with fully interconnected micro- (pore diameter $<10 \mu \mathrm{m}$ ) and macro-pores (pore diameter $>10 \mu \mathrm{m}$ ) allowing the scaffolds to be easily invaded by bone cells and blood vessels, thereby allowing for resorption and new bone tissue formation [14-16]. To create this open macroporous structure in the CPC scaffolds, several approaches have been used, such as, dissolution of highly soluble solid porogen, foaming, and use of a gaseous pore forming agent $[17,18]$. Although considerable amounts of macropores can be formed using these processes, many of these techniques may not be suitable for use with a putty or an injectable cement paste. In some cases the rapid dissolution of these highly soluble pore formers, prior to the complete setting of the cement, results in grafts that are mechanically inferior to adequately maintain their shape for in vivo use. To alleviate these problems, the use and incorporation of slowly degradable non-toxic and bio-compatible poly(lactic-co-glycolic acid) (PLGA) microspheres and fibers as a pore former into the CPC has been proposed in this study [19-22].

Cements that include PLGA microspheres as porogens (PLGA-CPCs composite cements) offer several unique advantages over other porogen containing cements. First, the degradation kinetics of PLGA microspheres and hence, the rate of pore formation in the composite cement can be controlled by meticulously changing the molecular weight and ratios of lactic acid to glycolic acid in the polymer [23, 24]. Second, drugs and growth factors can be easily incorporated inside the PLGA microspheres [25-28]. Third, as a result of the recent advances in model-aided design, degradable microspheres can now be pre-programmed effectively to release the desired drugs and growth factors at practically any rate and in a tailored sequential fashion over time [29-31]. Finally, the CPC itself can be used to release a desired molecule in addition to the entrapped molecules inside the PLGA microspheres [11, 32]. Thus, manifold possibilities exist to release different growth factors, proteins and drugs in a controlled manner from the 
PLGA-CPCs composite cements so that they can be used not only to engineer rapid bone regeneration but also for effective treatment of different bone related diseases such as osteomyelitis [33, 34]. To achieve this however, a thorough understanding of the effect of the PLGA micro-particles on the innate properties of the CPC and vice-versa is extremely important and is clearly warranted for the development of porous, biocompatible and drugs eluting resorbable CPCs $[35,36]$.

Recently, we have developed novel calcium phosphate based cement (ReCaPP), which exhibits excellent handling characteristics, bio-compatibility and in-vivo osteo-conductivity [37]. Furthermore, mannitol is used in this cement as a porogen (porous-ReCaPP), and the accompanying in-vivo results to date have showed considerable resorption of the scaffold and new bone regeneration in the rabbit ulnar model. The present study was thus designed to explore the pore forming ability of poly(lactic-co-glycolic acid) microspheres of various sizes by incorporating them into this calcium phosphate based cement, ReCaPP. This study also includes the effect of in-vitro degradation/erosion of the PLGA microspheres on the physical, chemical and structural characteristics of the composite cements. Another goal of this work was to study the release of antibiotic agents from composite cements, an area of research with limited studies in the past [27, 34]. To this end, we have therefore not only investigated but also effectively compared the in-vitro vancomycin release from calcium phosphate (PLGA-ReCaPP) cements in which vancomycin has been entrapped (i) inside the PLGA micro-spheres, (ii) in the ReCaPP powder and (iii) in the PLGA-ReCaPP mixed powder.

\section{Experimental section}

\subsection{Preparation of PLGA microspheres, cement powders and cement forming liquid}


PLGA microspheres and with or without vancomycin were prepared using a double emulsion-evaporation procedure and the details about the preparation techniques are given in the supplementary information section. The cement powders were prepared by mixing different calcium salts, disodium hydrogen phosphate and PLGA microspheres (of 40 and $100 \mu \mathrm{m}$ in diameter) and the detailed chemical compositions of the cements are given in Table S1 (see supplementary information). For making PLGA-cement composite powder (PLGA-ReCaPP), required amount of PLGA microspheres, was mixed with pre-formed ReCaPP powder. Two different sized PLGA microspheres were used to make PLGA-ReCaPP cements; the cement containing $40 \mu \mathrm{m}$ and $100 \mu \mathrm{m}$ of diameters of PLGA particles are labeled as PLGA-ReCaPP-40 and PLGA-ReCaPP-100, respectively, in this manuscript. For mannitol containing cements, mannitol as received powder was used to replace the PLGA microspheres. The liquid component of the ReCaPP, PLGA-ReCaPP-40, PLGA-ReCaPP-100 and Mannitol-ReCaPP cements consisted of a colloidal solution of nano-sized calcium phosphate (nano-CaPs) homogeneously dispersed in a buffer solution and the details of the nano-CaPs preparation can be found elsewhere [38, 39], and the details can be found in the supplementary information section.

\subsection{Cement preparation, cement hardening and fabrication of scaffolds}

Each of the cements was prepared by mixing $1.0 \mathrm{~g}$ of the cement powder or PLGA-Cement powders with $430 \mu \mathrm{l}$ of the nano-CaPs solution in a polystyrene pour boat. The setting time of the cement samples were measured following the ASTM (American Society for Testing and Materials) International method C-266 at 22 and $37{ }^{\circ} \mathrm{C}$ with a Gillmore apparatus. For measuring the setting time at $37{ }^{0} \mathrm{C}$ the molds filled with the cement paste were kept inside an incubator with relative humidity $<50 \%$. 
In order to characterize cements scaffolds in vitro, cylindrical specimens of $6 \mathrm{~mm}$ diameter and $15 \mathrm{~mm}$ of length were used. The cement pastes were put into Teflon molds and allowed to set for 60 minutes in an incubator. For in-vitro aging studies required numbers of set cement scaffolds were placed in $50.0 \mathrm{ml}$ Falcon polystyrene tubes and immersed under Phosphate Buffered Saline (PBS, without calcium and magnesium, pH 7.4 \pm 0.2 , 1X, Lonza BioWhittaker, USA) and placed inside an oven at $37^{\circ} \mathrm{C}$. PBS from these tubes was replaced in every $48 \mathrm{~h}$ with fresh PBS. After reaching a certain predetermined time point under PBS (e.g. 3, 6, 15 and 30 days), the scaffolds were dried in an oven for at $37^{\circ} \mathrm{C}$ for at least $48.0 \mathrm{~h}$. After completion of drying, the scaffolds were used for further characterization studies.

\subsection{Characterizations of the cement powders and scaffolds}

The cement powders, scaffolds obtained just after final cement setting time ( 0 day), and aged cement scaffolds under PBS for different time points (3, 6, 15 and 30 days) were characterized by X-ray diffraction (XRD) in a Philips X'Pert PRO diffractometer using $\mathrm{Cu} \mathrm{K}_{\alpha}$ radiation with a Si-detector (X'celerator). The phase identifications were carried out using HighScore Plus software (Version 3.0d, PANalytical B.V., Almelo, Netherlands) by means of JCPDS reference patterns (supplementary information). Crystallite size and quantitative phase compositions of the cements were calculated by means of total Rietveld refinement analysis with HighScore Plus and details about the refinement procedure are given in the supplementary information section.

FT-IR was performed on the powder samples using a Nicolet 6700 spectrophotometer (Thermo Electron Corporation) using a diamond ATR Smart orbit. Spectra were obtained at 1.0 $\mathrm{cm}^{-1}$ resolution averaging 32 scans. The surface morphology of powders and cement scaffolds were studied using scanning electron microscopy (SEM, Philips-XL30 FEG, Philips) operating 
at $10.0 \mathrm{kV}$ and all the samples used for SEM analysis were coated with Pd using a sputter coater system. The specific surface area and pore sizes distribution in the range of 2 and $100 \mathrm{~nm}$ of the aged hardened cements were measured using nitrogen adsorption at $77 \mathrm{~K}$ with an Automatic Physisorption Analyzer (BET, ASAP 2020, Micromeritics, Norcross, GA, USA). The particle diameters of the aged cements were calculated from the BET surface area measurement values assuming that all the particles to be perfectly spherical in shape. The true density $\left(\rho_{t}\right)$ values of the ReCaPP, PLGA-ReCaPP-40 and PLGA-ReCaPP-100 cements scaffolds were measured using gas displacement helium Pycnometer (AccuPyc II 1340, Micromeritics, Norcross, GA, USA). The bulk density or envelope density $\left(\rho_{\mathrm{e}}\right)$ values of the ReCaPP and PLGA-ReCaPP cements scaffolds were measured using Automatic Envelope Density Analyzer (GeoPyc 1360, Micromeritics, Norcross, GA, USA). The percentage porosity $\left(P_{\rho}\right)$ of a cement scaffold was calculates using the equation:

$P_{\rho}=\left[\left(1-\rho_{e} / \rho_{t}\right) \cdot 100\right] \%$

The pore size distribution of the ReCaPP, PLGA-ReCaPP-40 and PLGA-ReCaPP-100 cements in the range of $350 \mu \mathrm{m}$ and $6 \mathrm{~nm}$ were evaluated using Automated Mercury Porosimeter (Autopore IV 9500, Micromeritics, Norcross, GA, USA). The percent porosities calculated from the mercury intrusion $\left(P_{H g}\right)$ values were calculated using the equation:

$P_{H g}=\left[\rho_{e} . V_{H g} .100\right] \%$

where $\rho_{e}$ is the envelope density and $V_{H g}$ is the total mercury intrusion volume per gram. $V_{H g}$ can further split into two regions of interest [40, 41],

$$
\begin{aligned}
& P_{H g}=\rho_{e \cdot}\left[V_{300-1}+V_{1-0.006}\right] \cdot 100 \% \\
& P_{H g}=\left[P_{300-1}+P_{1-0.006}\right] \cdot 100 \%
\end{aligned}
$$


where $V_{300-1}$, and $V_{1-0.006}$ are the mercury intrusion volume per gram in the specific pore size intervals (in $\mu \mathrm{m}$ ). Therefore, $P_{300-1}$, and $P_{1-0.006}$ are the porosities for each of those size intervals.

\section{4. $\quad$ pH measurements, mass loss and dissolution studies}

Cylindrical specimens of ReCaPP, PLGA-ReCaPP-40, PLGA-ReCaPP-100 and pure PLGA were used for $\mathrm{pH}$, mass loss and dissolution measurements. For pure PLGA group, the weight of PLGA used was comparable to the amount PLGA used to make the PLGA-ReCaPP-40 and PLGA-ReCaPP-100 composite cements. For all these studies samples were immersed in PBS of $\mathrm{pH} 7.4$ and kept at a temperature $37^{\circ} \mathrm{C}$ and $20.0 \mathrm{ml}$ of PBS solution was used for each gram of the cements. Two different strategies were used for $\mathrm{pH}$ measurements; in the first case (static environment) the PBS was not changed during the entire life span of the $\mathrm{pH}$ studies, whereas in the second case (dynamic environment) the PBS was changed every $48( \pm 6)$ hours and was replenished by equal volume of fresh PBS. The $\mathrm{pH}$ value was monitored upon degradation using a $\mathrm{pH}$ meter ( $\phi$ 350, Beckmann) and three samples were used for each group. For mass loss at each degradation time three samples for each group were used and PBS was changed every $48( \pm 6)$ hours. The mass loss was calculated according to following equation:

$M_{l}=\left[\left(M_{i}-M_{d}\right) / M_{i}\right] 100 \% \ldots \ldots . .(5)$

where $M_{i}, M_{d}$ and $M_{l}$ are the initial mass, dry mass and mass loss, respectively.

For calcium dissolution studies, Ca concentration was determined using Inductively Coupled Plasma (ICP, iCAP 6000 series, Thermo Electron Corporation) and the details are given in the supplementary information section. For each group, three samples $(n=3)$ were taken and each sample was measured three times for the determination of the ion concentrations. 


\subsection{Vancomycin release studies}

Release kinetics of vancomycin was determined by incubating drug containing composites in $1 \mathrm{ml}$ of phosphate buffered saline (PBS) at $37{ }^{\circ} \mathrm{C}$. At regular time intervals, the amount of drug released was determined by measuring absorbance at 240nm (Spectramax M5, Molecular Devices, Sunnyvale, CA). Release profiles were plotted as cumulative percentages of the theoretical maximum

\section{Results}

\subsection{Preparation and Morphology of Cement}

The details related to the cement compositions are given in Table S1 (see supplementary information). The initial and final setting times of the ReCaPP cement were measured to be $9 \pm 2$ min and $25 \pm 3 \mathrm{~min}$ at $25{ }^{\circ} \mathrm{C}$ for a powder to liquid (P/L) ratio of $2.22 \mathrm{~g} / \mathrm{ml}$ and these setting times were observed to decrease to $7 \pm 2 \mathrm{~min}$ and $19 \pm 3 \mathrm{~min}$ when the cement was allowed to set inside an incubator at $37{ }^{\circ} \mathrm{C}$. The setting times were also observed to increase with a decrease in $\mathrm{P} / \mathrm{L}$ ratio. The setting times for the PLGA-ReCaPP cements were longer compared to the cements made with only pure $\mathrm{ReCaPP}$ for similar $\mathrm{P} / \mathrm{L}$ ratios and setting temperatures. The observed initial and final setting times for the PLGA-ReCaPP-40 cement were measured to be 10 $\pm 2 \mathrm{~min}$ and $28 \pm 3 \mathrm{~min}$ at $37^{\circ} \mathrm{C}$ with no significant differences observed for the cements synthesized using PLGA namely, PLGA-ReCaPP-40 and PLGA-ReCaPP-100 cements.

Degradation of the ReCaPP cements with or without PLGA microspheres was monitored using scanning electron microscopy (SEM). Fracture surface analysis of the PLGA-ReCaPP cement (containing either 40 or $100 \mu \mathrm{m}$ sized polymer particles) shows the development of macropores (Figs. 1 and 2). SEM images of the as formed PLGA-ReCaPP scaffolds (Figs. 1a 

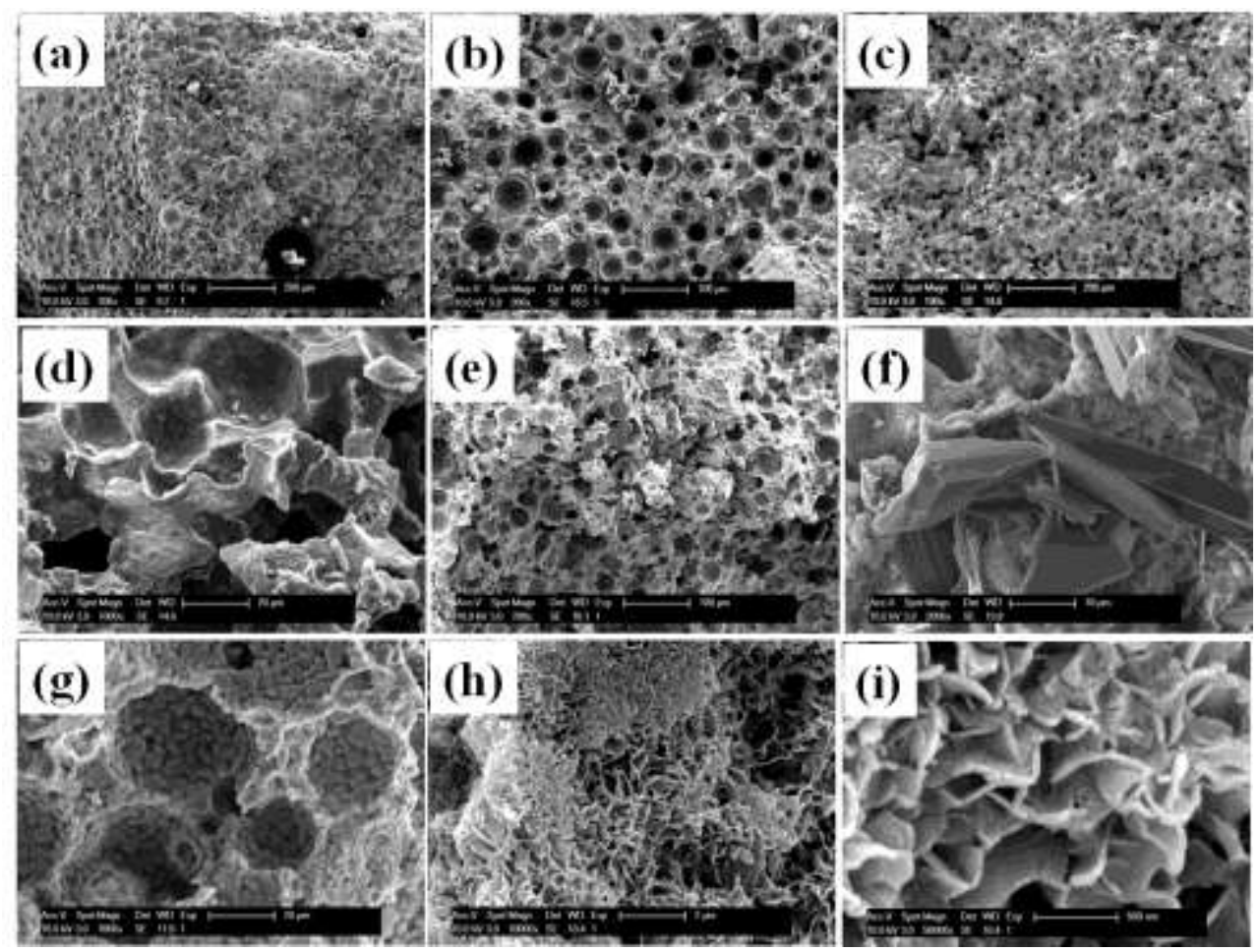

Fig. 1. SEM images at different magnifications of PLGA-ReCaPP-40 cement after ageing under PBS at $37{ }^{\circ} \mathrm{C}$ for different time periods (a) 0 day, (b) 6 days, (c) 15 days, (d) 15 days at high magnification showing PLGA film on cement particles, (e) 30 days and (f) 30 days at high magnification showing DCPD crystals formation, (g) 30 days showing interconnecting macro-pores (h) 30 days at high magnification showing pellets like structures and (i) 30 days at very high magnification showing formation of nano-structured HAp. The scale bar in (a and c) is $200 \mu \mathrm{m}$, in (b and e) 100 $\mu \mathrm{m}$, in (d and g) $20 \mu \mathrm{m}$, in (f) $10 \mu \mathrm{m}$, in (h) $2 \mu \mathrm{m}$ and in (i) it is $500 \mathrm{~nm}$.

and 2a; 0 day) show the PLGA microspheres intact and embedded in the ReCaPP cement. Incubation of PLGA-ReCaPP cements in PBS (aging) resulted in partial degradation of the PLGA microspheres at 6 (Figs. 1b and 2b) and 15 days (Figs. 1c and 2c). Presence of thick layers of PLGA was observed on the cement particles after 15 days of aging (Fig. 1d). Further, PLGA particles were observed to be completely degraded following 30 days of aging, which resulted in the formation of macropores of sizes that correlated with the size of the degraded particles (Figs. 1e and 2d). Fracture surface analysis of the ReCaPP cement without PLGA 

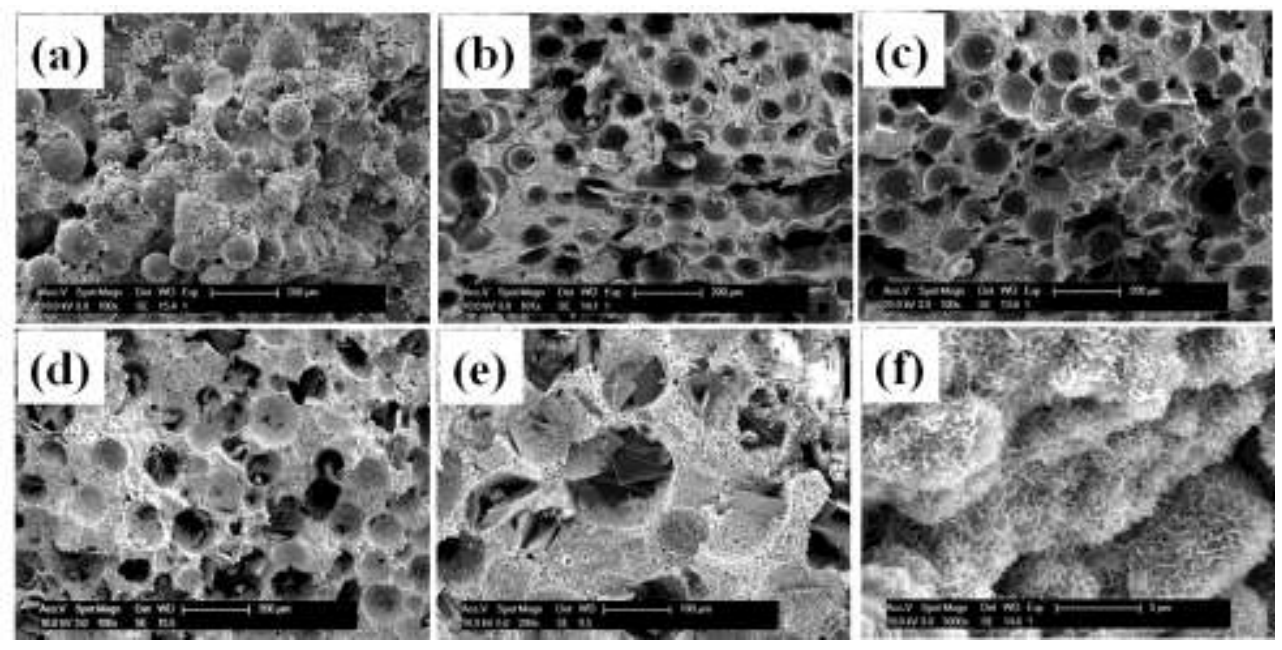

Fig. 2. SEM images at different magnifications of PLGA-ReCaPP-100 cement after ageing under PBS at $37^{\circ} \mathrm{C}$ for different time periods (a) 0 day, (b) 6 days, (c) 15 days, (d) 30 days, (e) 30 days showing DCPD crystals formation, and (f) 30 days at higher magnification showing formation of nano-structured HAp. The scale bar in (a-d) is $200 \mu \mathrm{m}$, in (e) $100 \mu \mathrm{m}$, in (f) $5 \mu \mathrm{m}$.

shows the absence of any such macropores (Fig. S1, supplementary information). Interestingly, after 30 days of aging both the PLGA-ReCaPP cements exhibited formation of some platelets or disk-like micro-crystalline particles (Figs. 1e-f and 2d-e). EDX measurements to determine the elemental $\mathrm{Ca}$ and $\mathrm{P}$ amounts on these platelets revealed a calcium-to-phosphorous ratio $(\mathrm{Ca} / \mathrm{P})$ of approximately 1.0 reflecting the presence and formation of brushite or di-calcium phosphate dehydrated $\left(\mathrm{CaHPO}_{4} \cdot 2 \mathrm{H}_{2} \mathrm{O}\right.$, DCPD) phase (data not shown). Additionally, it was observed that each of the macropores in the PLGA-ReCaPP scaffolds were either separated from one another by a thin layer of CPC or appeared to be interconnected (Fig. 1g). All of the PLGA-ReCaPP cements, after aging exhibited the formation of whiskers and plate-shaped nano-crystalline hydroxyapatite (HAp) particles (Figs. 1h-i and 2f) on the surface and between the particles. EDX measurements to determine the elemental contents again conducted (data not shown) on these whiskers and plate-shaped nano-crystalline particles yielded $\mathrm{Ca} / \mathrm{P}$ ratios of approximately 1.67 
characteristic of hydroxyapatite (HAp). Formation of the whisker-like crystals of hydroxyapatite (HAp) entangled between the micron-sized particles was also observed in the ReCaPP cement without any PLGA microspheres (Fig. S1, supplementary information). It is well known that calcium phosphate cements are formed by the dissolution of the $\alpha$-TCP particles in the mixing liquid and precipitation of the HAp crystals is observed once the solution has become supersaturated ideal for formation of HAp [42, 43].

\subsection{Porosity of Cement}

The cumulative mercury intrusion volumes of the ReCaPP, PLGA-ReCaPP-40 and PLGA-ReCaPP-100 samples with aging times are shown in Fig. 3a. The total intrusion volumes for the PLGA-ReCaPP cements were always higher than the pure ReCaPP cements devoid of the PLGA polymer (without microspheres). The values of the total intrusion volumes for the ReCaPP cements did not change much with aging times (Fig. 3a-i); whereas for PLGA-ReCaPP cements, the total intrusion volume increased slightly up to 15 days of aging (Figs. 3a-ii and iii). The total mercury intrusion volume however increased considerably between 15 and 30 days of aging (Figs. 3a-ii and iii) and is likely consistent and attributable to the degradation of the PLGA microspheres. The pore size distributions of the ReCaPP cements with aging time demonstrate the presence of micropores in the 100 to $6 \mathrm{~nm}$ range and an absence of macropores in the 100 to $1 \mu \mathrm{m}$ range (Fig. 3b-i). The PLGA-ReCaPP cements on the other hand, exhibited a bimodal distribution of the pore sizes after 30 days of aging, with the PLGA-ReCaPP-40 cements showing macropores in the $10-40 \mu \mathrm{m}$ range and the PLGA-ReCaPP-100 cements showing macropores in the 10-100 $\mu \mathrm{m}$ range. In addition to large macropores there were minor contributions from the micropores in the 100-6 nm size range (Figs. 3b-ii and iii). Porosity data 
(different pore sizes intervals as well as the total porosity of the various samples) were produced using equation 3 and 4 and are listed in Table S2 (see supplementary information). This Table shows that PLGA-ReCaPP cements exhibited much higher porosity values compared to ReCaPP cements following degradation of PLGA and the large porosities were in general due to pores in the range of 300-1 $\mu \mathrm{m}$. There is an increase in the percentage porosity values $\left(P_{H g}\right)$ with aging times for both the PLGA-ReCaPP cements and this change is observed to be very high between 15 and 30 days of aging. These results thus indicate that most of the PLGA particles likely degrade between 15 and 30 days of aging and are consistent with the SEM results (Figs. 1 and 2). The Table S2 (see supplementary information) also indicates that the non-porous ReCaPP cements contained mostly pores of diameter below $100 \mathrm{~nm}$ and $P_{H g}(\%)$ values did not change much with aging time.
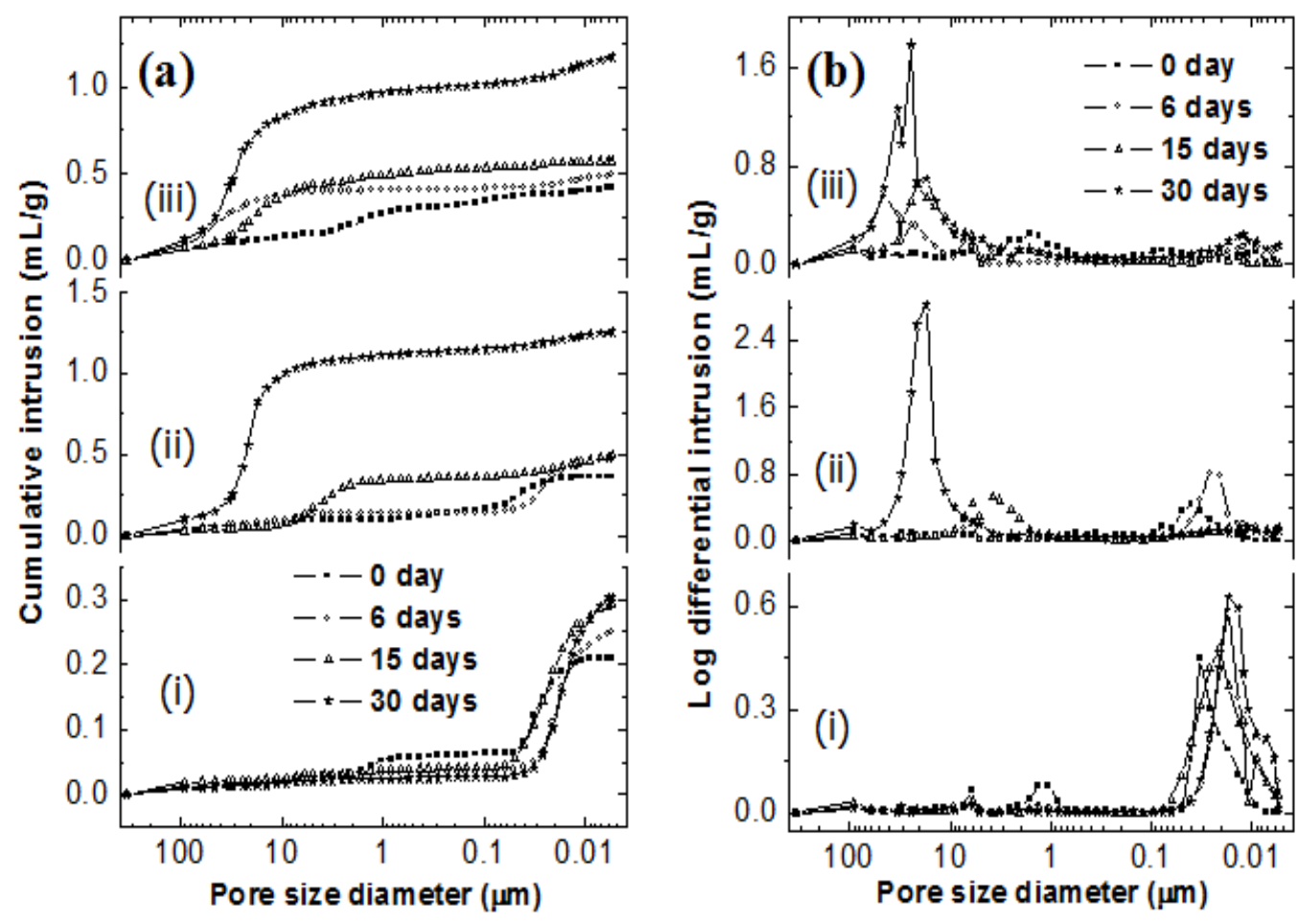

Fig. 3. (a) Mercury intrusion volume and (b) pore size distribution of (i) ReCaPP, (ii) PLGA-ReCaPP-40, (iii) PLGA-ReCaPP-100 cement samples after ageing under $\mathrm{PBS}$ at $37^{\circ} \mathrm{C}$ for different time periods. 
The measured BET surface area $\left(\mathrm{S}_{\mathrm{BET}}\right)$ of the starting powders for the ReCaPP and PLGA-ReCaPP cements were found to be very similar and in the range of 0.8 to $1.2 \mathrm{~m}^{2} / \mathrm{g}$. The surface area of the as formed ReCaPP cement ( 0 day) increased considerably in comparison to the starting powder and increased further with aging times (Fig. 4a). For the PLGA-ReCaPP cements, the $\mathrm{S}_{\mathrm{BET}}$ remarkably did not change much with aging time up to 15 days and the effective surface areas were substantially lower than ReCaPP cements due to the presence of the micron-sized partially degraded PLGA particles. However, after 30 days of aging, the surface area of all the ReCaPP and PLGA-ReCaPP cements noticeably increased and appeared to be similar. The particle sizes calculated from the $\mathrm{S}_{\mathrm{BET}}$ values for the ReCaPP and PLGA-ReCaPP cements as a function of aging time are given in Table $\mathbf{S 3}$ (see supplementary information). The calculated particle sizes clearly show that the formed particles are in the nanometer range $(<100$ $\mathrm{nm}$ ) after 30 days of aging. The plots of true density and envelope density values for the ReCaPP and PLGA-ReCaPP cements with aging times are shown in Figs. $\mathbf{4 b}$ and $\mathbf{4 c}$, respectively. The true density value $\left(\rho_{t}\right)$ of the ReCaPP was higher than the PLGA-ReCaPP in the as prepared cement due the presence PLGA, which has a lower density $(1.34 \mathrm{~g} / \mathrm{cc})$ compared to $\alpha$-TCP $(3.14$ $\mathrm{g} / \mathrm{cc}$ ) or HAp $(3.16 \mathrm{~g} / \mathrm{cc})$. The $\rho_{\mathrm{t}}$ value of the ReCaPP cement did not change much with aging. The $\rho_{\mathrm{t}}$ values for both the PLGA-ReCaPP cements were also almost similar and did not change much upon aging up to 15 days. On further aging, the true density values of the composite cements increased to the true density value of the ReCaPP cement (Fig. 4b), and these results indicate the complete dissolution of the PLGA particles in the PLGA-ReCaPP cements. The envelope or apparent density $\left(\rho_{\mathrm{e}}\right)$ values at different aging times for the PLGA-ReCaPP cements were found to be always lower than the ReCaPP indicating porous nature of the PLGA-ReCaPP cements (Fig. 4c). The $\rho_{\mathrm{e}}$ values for all the cements were found to be decreasing slightly with 

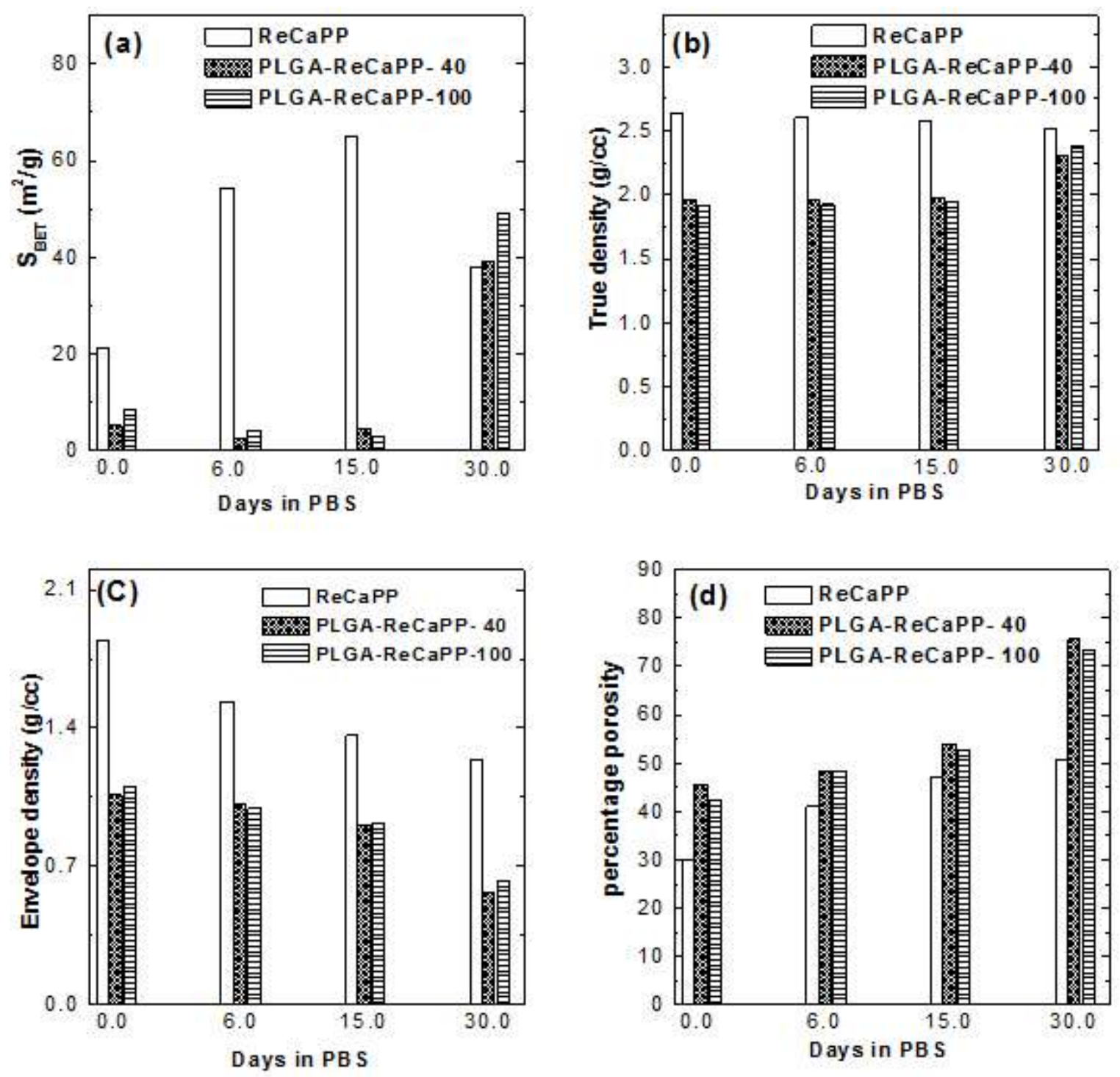

Fig. 4. Different physical parameters of ReCaPP and PLGA-ReCaPP-40 and PLGAReCAPP-100 cements after ageing under PBS at $37{ }^{\circ} \mathrm{C}$ for different time periods (a) specific surface area, (b) true density, (c) envelope density and (e) percentage porosity calculated from density values.

increasing aging time. The change in percentage porosity values calculated using equation- 1 with different aging times for all the cement scaffolds are shown in Fig. 4d. The percentage porosity values of the PLGA-ReCaPP cements were always found to be higher than the ReCaPP cement and there was a large change in this value between 15 and 30 days of aging and this was most likely due to the complete degradation of the PLGA microspheres as has been observed and confirmed by SEM images. 


\section{3. $\quad p H$ and Mass Changes}

The change of $\mathrm{pH}$ values of the PLGA-ReCaPP-40, PLGA-ReCaPP-100 and PLGA scaffolds in static PBS suggests that the values decrease rapidly in the first 400 hours, following which subsequently, the pH decreases only slightly with time (Fig. 5a). Fig. 5 also suggests that the $\mathrm{pH}$ for pure PLGA scaffold could reach as low as $\sim 2.0$, whereas in contrast, for the PLGAReCaPP cements, the $\mathrm{pH}$ decreases to $~ 4.0$. For $\mathrm{ReCaPP}$ cement the $\mathrm{pH}$ value increases slightly with time and reaches a value of $\sim 7.9$ after 900 hours (Fig. 5a). In order to mimic the change of the $\mathrm{pH}$ values of the scaffolds in-vivo, the PBS was changed every 48 hours and replenished with
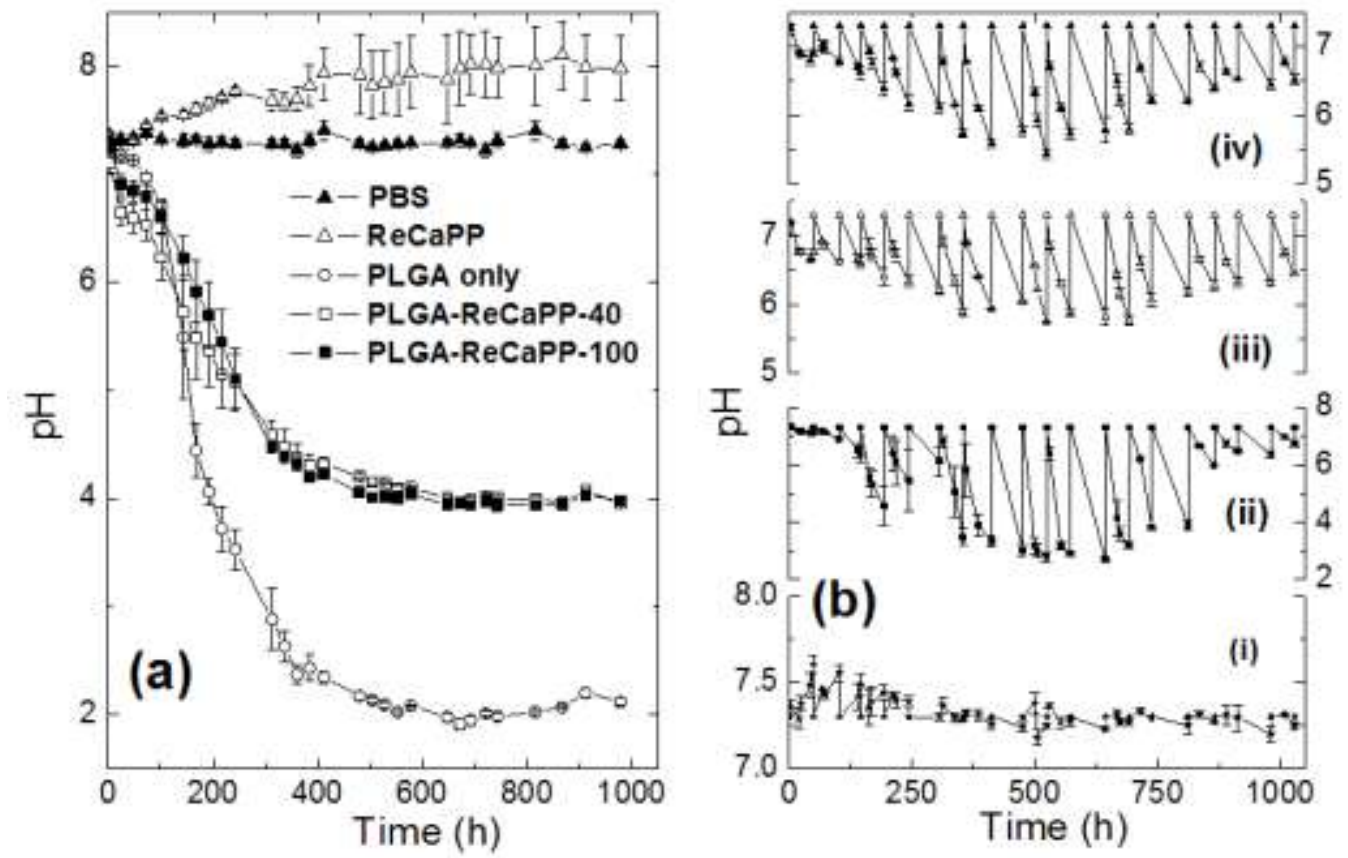

Fig. 5. (a) change of $\mathrm{pH}$ with time of the PBS alone, ReCaPP cement, PLGA scaffold, PLGA-ReCaPP-40 cement, PLGA-ReCaPP-100 cement under static environment; (b) change of $\mathrm{pH}$ with time of the (i) ReCaPP, (ii) PLGA scaffold, (iii) PLGA-ReCaPP-40 and (iv) PLGA-ReCaPP-100 under dynamic environment.

fresh PBS. The $\mathrm{pH}$ variation under this dynamic condition for the ReCaPP scaffolds was small and observed to change only between 7.2 and 7.5 (Fig. 5b-i). For the pure PLGA scaffolds, the 
$\mathrm{pH}$ was observed to decrease steadily with time and maximum variations in the $\mathrm{pH}$ was observed between 300 and 800 hours (Fig. 5b-ii). After 800 hours of aging in PBS, the pH was observed to increase. The $\mathrm{pH}$ changed from 7.4 to 3.0 within 48 hours for the pure PLGA scaffolds when the aging times reached approximately, 520 hours. For both the PLGA-ReCaPP cements, the change in $\mathrm{pH}$ values was limited between 7.4 to 5.5 under dynamic conditions (Figs. 5b-iii and iv).
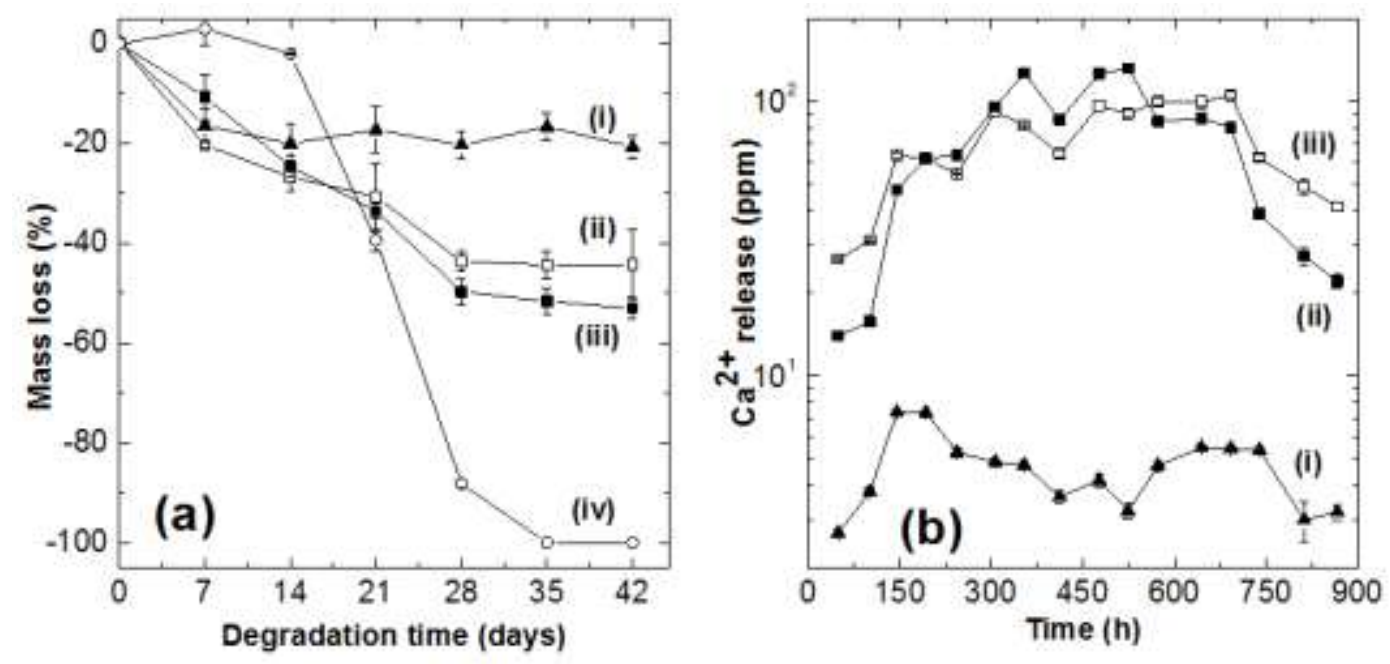

Fig. 6. (a) Degradation behaviors with time for (i) ReCaPP, (ii) PLGA-ReCaPP-40, (iii) PLGA-ReCaPP-100 and (iv) PLGA scaffold in PBS; (b) calcium ion release for every 48 hours in PBS with time for (i) ReCaPP, (ii) PLGA-ReCaPP-100, and (iii) PLGAReCaPP-40.

Fig. 6a shows the mass loss of the different scaffolds with aging time under dynamic conditions. ReCaPP exhibited a mass loss of $18 \%$ in the first seven days and subsequently the change in mass was insignificant (Fig. 6a-i). The two PLGA-ReCaPP cements also exhibit similar mass loss trend with a mass loss of $\sim 50 \%$ after 28 days of aging (Figs. 6a-ii and iii). This weight loss is most likely due the complete dissolution of the PLGA, calcium sulfate and disodium hydrogen phosphate. Pure PLGA scaffolds exhibit a slight increase in mass initially, but lose $80 \%$ of the mass within 28 days (Figs. 6a-iv). All the pure PLGA scaffolds were 
completely degraded within 35 days of aging. Dissolution behaviors of ReCaPP and PLGAReCaPP cements in PBS of pH 7.4 at $37{ }^{\circ} \mathrm{C}$ with immersion time are shown in Fig. 6b. The rate of calcium released at every 48 hours and for both the PLGA-ReCaPP scaffolds, the $\mathrm{Ca}^{2+}$ concentrations were much higher than that of ReCaPP cements at a particular aging time. No

significant differences in the $\mathrm{Ca}^{2+}$ release rate could be observed for the PLGA-ReCaPP-40 and PLGA-ReCaPP-100 cements (Figs. 6b-ii and iii).

\subsection{Characterization of Cement}

Fig. 7 shows the XRD patterns collected on the ReCaPP and PLGA-ReCaPP-100 cements following immersion in $\mathrm{PBS}$ at $37^{\circ} \mathrm{C}$ to age for different time periods. The XRD results clearly show (Fig. 7a) the presence of $\alpha$-TCP phase in all of the ReCaPP samples (up to 30 days immersion in PBS) including the small fraction of $6 \mathrm{wt} . \%$ present after 30 days which indicates that the cement took more than 30 days to completely convert to hydroxyapatite (HAp). In contrast, the $\alpha$-TCP phase was absent in the PLGA-ReCaPP-100 cement 30 days following immersion in PBS (Fig. 7b). Further, at the 30-day time-point only HAp and DCPD phases were observed. The fractions of each phase present were estimated using semi-quantitative Rietveld refinement analysis and the amounts of $\alpha$-TCP, DCPD and HAp present in the cement for each immersion time points are given in Table $\mathbf{S 3}$ (see supplementary information). The analyses however does indicate that the wt.\% of $\alpha$-TCP phase present decreased with increase in aging time in PBS for all the cements and the amount of DCPD phase increased for the composite PLGA cements with increasing immersion times reflecting the effect of $\mathrm{pH}$ and the particle size affecting the transformation reaction kinetics. The average crystallite sizes calculated for the transformed HAp phase at different time points indicates that the HAp crystallite sizes did not 
change significantly with aging time for all these cements. Interestingly, the HAp crystallite sizes for the PLGA-ReCaPP cements were only slightly lower than the ReCaPP cements.
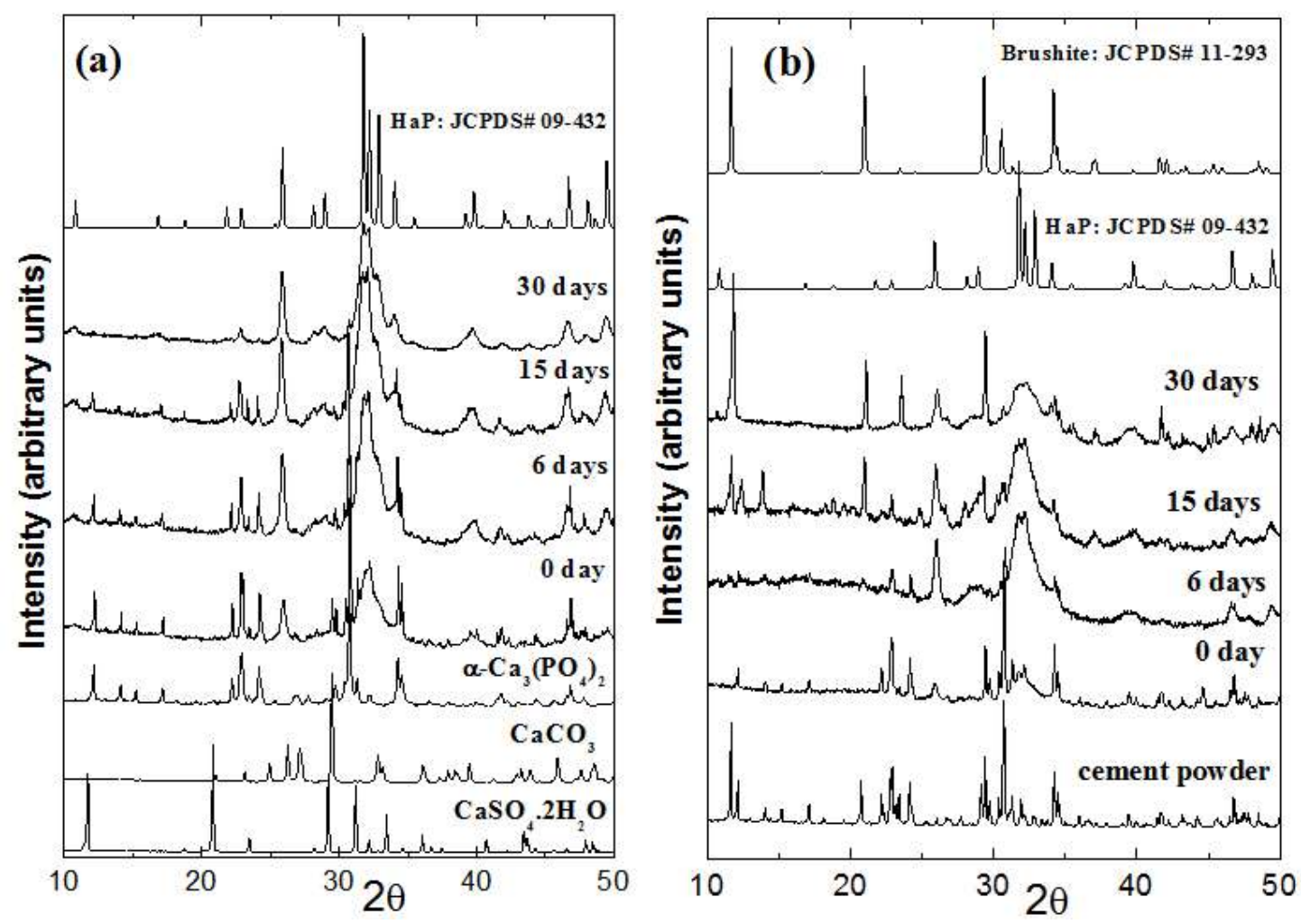

Fig. 7. X-ray diffraction patterns of (a) ReCaPP and (b) PLGA-ReCaPP-100 cement after aging under $\mathrm{PBS}$ at $37^{\circ} \mathrm{C}$ for different time periods.

The FTIR spectra (Fig. 8) of the ReCaPP and PLGA-ReCaPP-100 cements with aging times show the presence of the different vibrational modes of $\mathrm{PO}_{4}{ }^{3-}$ centered approximately $800-1200$ and 500-700 $\mathrm{cm}^{-1}$. Furthermore, the presence of bands at 1650, 1460 and $1415 \mathrm{~cm}^{-1}$ indicate the presence of carbonate group [44]. The presence of a band $\sim 870 \mathrm{~cm}^{-1}$ is due to carbonate and $\mathrm{HPO}_{4}{ }^{2-}$, and these carbonates peaks were absent in the commercially obtained HAp (Fig. 8a-vi), a reflection of the interaction of $\mathrm{CO}_{2}$ present in the mixing liquid and the ambient environment. The FTIR spectrum of the as prepared PLGA-ReCaPP-100 cement (Fig. $\mathbf{8 b}$-ii, 0 day) showed the presence of additional PLGA peaks (Fig. 8b-i) in addition to the bands 

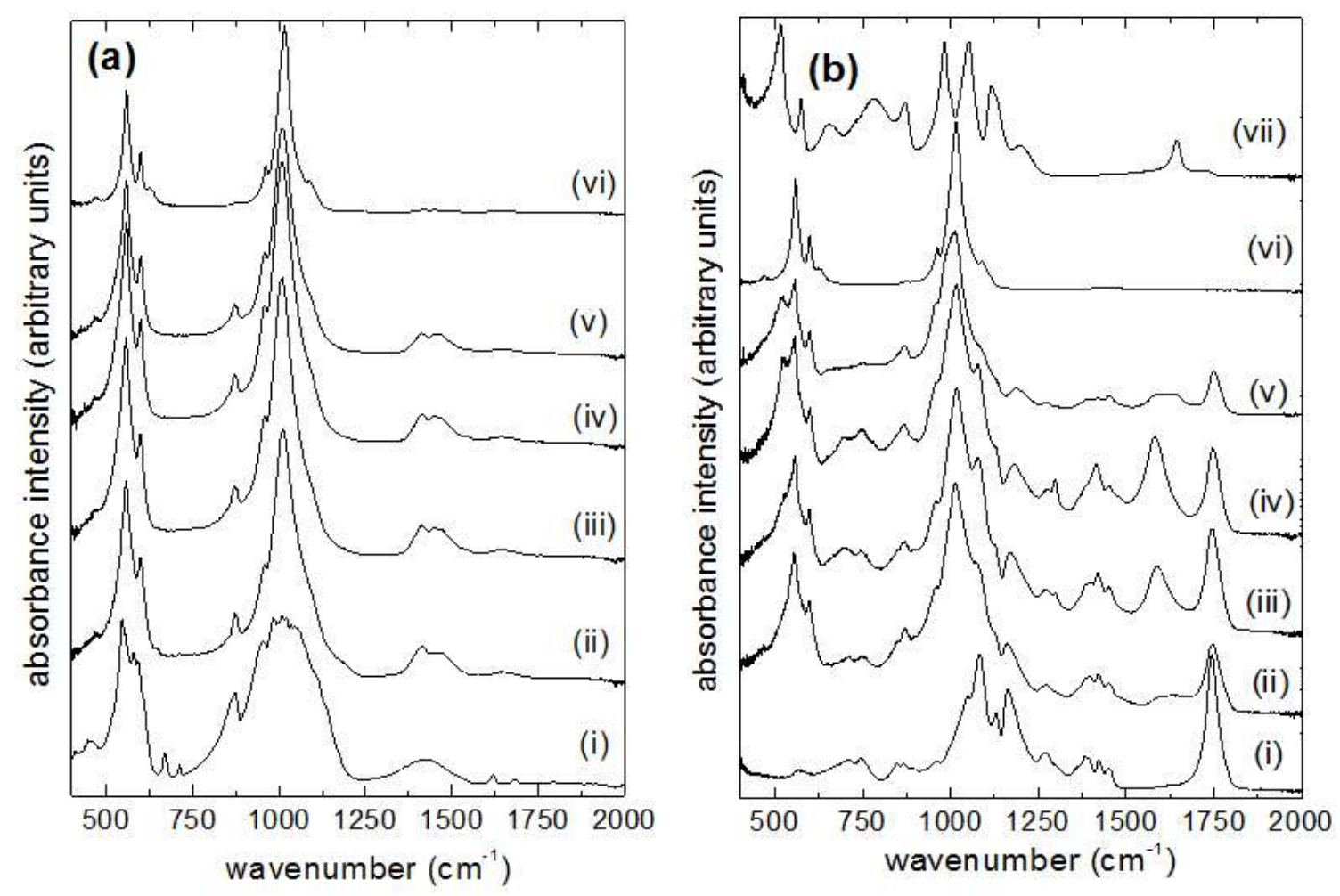

Fig. 8. FTIR spectra of cements after ageing under PBS at $37{ }^{\circ} \mathrm{C}$ for different time periods (a) ReCaPP cement (i) cement powder, (ii) 0 day, (iii) 6 days, (iv) 15 days (v) 30 days and (vi) pure HAp; (b) PLGA-ReCaPP-100 cement (i) $100 \mu \mathrm{m}$ PLGA powder (ii) 0 days, (iii) 6 days, (iv) 15 days and (v) 30 days (vi) pure HAp and (vii) pure DCPD.

observed for the ReCaPP cements. Typical bands indicating presence of ester carbonyl stretch $(\mathrm{C}=\mathrm{O})$ at $1745 \mathrm{~cm}^{-1}$ and $\mathrm{C}-\mathrm{O}-\mathrm{C}$ stretch $1080 \mathrm{~cm}^{-1}$ could be observed in all the aged composite cements. However, the intensity of these bands decreased with increase in aging time. The weak peak at $1745 \mathrm{~cm}^{-1}$ possible indicates the presence of trace amounts of PLGA even after 30 days of aging (Fig. 8b-v). The PLGA-ReCaPP-100 cement samples following 15 and 30 days of aging also showed the appearance of a new peak at $520 \mathrm{~cm}^{-1}$ and this was due to the presence of brushite in these cements $[45,46]$. The other bands due to the vibrational modes of phosphate moieties corresponding to the brushite phase were observed to be in the same range as that of the phosphates corresponding to HAp phase and thus, it was not feasible to separate and characterize them independently for each phase due to the simultaneous presence of both phases. 


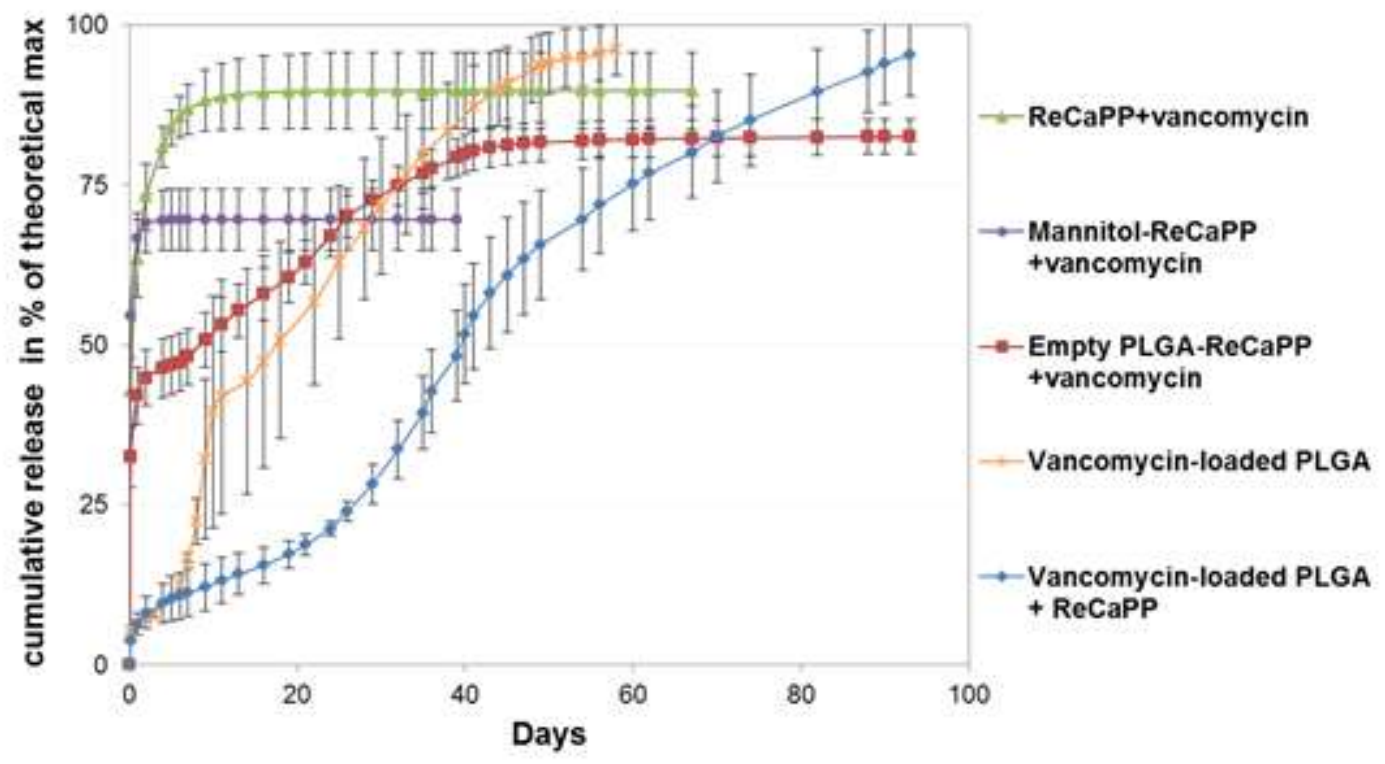

Fig. 9. Release profiles of vancomycin from various cement composites. Error bars show standard deviations from the mean based on at least $n=3$ cement composite samples.

\subsection{Release Studies}

Finally, we characterized the sustained in vitro release of a model active agent (vancomycin) from the PLGA- ReCaPP cement composites (Fig. 9). The kinetics of vancomycin release from the cements with or without mannitol as a pore forming agent showed a burst profile with the drug releasing in $\sim 2$ days for the cements containing mannitol and $\sim 7$ days for cements without mannitol. In contrast, the cements containing vancomycin and empty PLGA microspheres showed an initial burst ( $44 \%$ of drug releasing within 2 days) followed by a sustained release for over 40 days. Interestingly, cements containing vancomycin encapsulated in PLGA 
microspheres showed sustained release for 90 days. The release kinetics of vancomycin loaded in the PLGA microspheres is also shown in Fig. 9 for reference.

\section{Discussion}

It is known that bone defects larger than a certain critical size require a support structure, such as a scaffold, to heal completely $[1,2]$. An appropriate pore structure, porosity, pore size distribution, and three dimensional interconnected porous networks are important and necessary characteristics for scaffolds to support the bone regeneration process [14-16, 47, 48]. Several previous studies have reported the formation of CPC-PLGA composites and their in-vitro and invivo degradation. It has been shown that the in-vitro and in-vivo degradation, pore formation rate, and bone formation ability of these composites cements depend on several factors related to the presence of both the PLGA and CPC. For example, inclusion of dense PLGA microspheres in the PLGA-CPC resulted in enhanced porosity compared to hollow microspheres [22]. Moreover, the physicochemical properties such as molecular weight, lactic to glycolic acid ratio, and end group functionalization also strongly affect the overall degradation of composite cements [49-51]. However, a recent in-vivo study also reported that the difference in PLGA microsphere size and the CPC composition did not result in significant change in the scaffold degradation and bone in growth [35]. Furthermore, the release of antibiotics from the PLGACPCs also depends on several factors other than just the intrinsic properties of the PLGA used to entrap the drugs $[27,34]$ or biologics $[25,52,53]$. These studies suggest that the interactions between the PLGA microspheres and the CPC are complex, warranting further analysis. Thus, the objective of the work described herein was primarily to investigate the use of PLGA particles as pore forming agents in a scaffold generated from a new calcium phosphate based cement, 
ReCaPP [37], as well as to understand the release of the model drug, vancomycin, from these composite cements.

Pore size distribution in the scaffolds is primarily controlled by the size of the pore forming agent used [17, 18]. Scanning electron micrographs (Figs. 1 and 2) and mercury porosimetry measurements (Fig. 3) confirm that the pore sizes observed in PLGA-ReCaPP cements conform to the size of the PLGA microspheres, with the $100 \mu \mathrm{m}$ PLGA microspheres resulting in larger pores compared to the $40 \mu \mathrm{m}$ PLGA microspheres. Additionally, the degradation of PLGA from PLGA-ReCaPP composite cements was not homogenous. It is well known that PLGA degrades by hydrolysis and the degradation byproducts containing carboxyl end groups can easily diffuse into the solution from the sample surface $[54,55]$. However, carboxylic acids produced via degradation of PLGA microspheres increase local acidity, resulting in accelerated heterogeneous degradation and erosion. This heterogeneous degradation can lead to the formation of relatively un-degraded PLGA envelope or PLGA sheets covering the cement surface. Indeed, these PLGA sheets were observed by SEM in the PLGA-ReCaPP composite cements (Fig. 1d). Additionally, degradation of PLGA under static and dynamic environments, as expected, decreases the $\mathrm{pH}$ of the surrounding media over time (Fig. 5). The higher $\mathrm{pH}$ values for the PLGA-ReCaPP composites were most likely due the buffering effect of the $\alpha$-TCP and HAp particles. The protons generated from the released acidic byproducts of PLGA possibly interacts with the phosphates ions present in the lattices of the $\alpha$-TCP and HAp particles and thus leading to the presence of $\mathrm{HPO}_{4}{ }^{2-}$ and $\mathrm{H}_{2} \mathrm{PO}_{4}^{-}$anions. The formation of these divalent and monovalent phosphate anions not only decrease the $\mathrm{pH}$ of the surrounding media (Fig. 5), but also increase the dissolution of the calcium phosphate cements (Fig. 6) causing increase in the soluble $\mathrm{Ca}^{2+}$ released. XRD results indeed showed the formation of brushite (Fig. $7 \mathbf{~ b}$ ) in the PLGA-ReCaPP 
composite cements as a consequence of the reduced $\mathrm{pH}$ and the weight percentage of this brushite phase also increases with the increase in degradation of the PLGA microspheres with time (Table S3, supplementary information). The enhanced rate of dissolution of the composite cements compared to ReCaPP alone was further confirmed by the release of $\mathrm{Ca}^{2+}$ ions as measured by the ICP (Fig. $\mathbf{6 b}$ ). The total numbers of $\mathrm{Ca}^{2+}$ ions released from the composite cements were at least ten fold higher compared to the non-porous ReCaPP cement alone. All these results thus clearly demonstrate that although PLGA degradation accelerates the degradation of ReCaPP in the composite cements, $\mathrm{ReCaPP}$ however, does not appear to affect the PLGA degradation rate significantly $[22,35,51,56]$. The results along with the release data in Fig. 9 suggest an association of vancomycin with brushite formed in the cement due to PLGA degradation or with the degraded PLGA components (in the case of vancomycin mixed with empty PLGA microspheres and CPC), leading to a slower than expected release that lasts 4-6 weeks instead of a burst release pattern. Additionally, given that the degradation products of the PLGA appears to accelerate the ReCaPP dissolution, it should favorably influence the resorption of these porous scaffolds thus facilitating the ReCaPP to resorb over much shorter times than the normal, extremely long dissolution rates of the apatite CPCs $[22,51,56]$, which is also beneficial for this application.

Porosity and a highly interconnected network of pores are other important characteristics of scaffolds for bone regeneration. Theoretical and experimental studies have shown that spheres form fully interconnected chains of particles when the volume fraction of the spheres embedded in the solid matrix reaches $0.4[19,57]$. The volume fractions of the PLGA microspheres in these composite cements, calculated using the density of PLGA $(1.34 \mathrm{~g} / \mathrm{cc})$ and cement $(3.1 \mathrm{~g} / \mathrm{cc})$, was close to 0.58 . Thus the macropores formed after the complete dissolution of the PLGA in these 
composite cements should be likely contiguous and fully interconnected. SEM images (Figs. 1g and 2d) showed the formation mostly interconnected pores in the 30 days aged scaffolds, however, some of the pores appeared to be only partially interconnected. This is most likely due to the wetting and formation of a thin shell of the cement paste between the PLGA microspheres during the cement setting and hardening process. In most cases, this CPC shells have been broken during the PLGA degradation, leading to interconnected pores. On the other hand, in some cases the thin shell of HAp or DCPD remained intact and separate from the adjoining macropores. In addition to the presence of interconnected macro-porosity in these composite scaffolds, these cements are highly porous as found by the mercury intrusion (Table S2, supplementary information) and by the density based porosity measurements (Fig. 4). Moreover, Table S2 indicates that in the composite cements the contribution of the macro-porosity (1-300 $\mu \mathrm{m})$ towards the total porosity is much more compared to the micro-porosity $(1-0.006 \mu \mathrm{m})$ particularly after 30 days aging in PBS. The highly interconnected macroporous structures in these composite cements could potentially support the osteogenic cell migration, proliferation and new bone generation throughout the entire volume of the highly porous scaffolds when used as a bone void filler to repair critical sized bone defects. The presence of micro-pores also supports the nutrients flow and fluid circulation throughout the interior of the scaffolds and thus facilitates cell growth as well as the dissolution of the PLGA particles and the calcium phosphate phases $[14-16,47,48]$.

An additional promising and translational feature of the cement composites rendering them amenable for possible therapeutic treatment is the sustained delivery of drugs and growth factors to aid not only in tissue growth, but also promote healing and prevent infections. One potential delivery method for these agents is mixing them with the cement during fabrication while 
allowing the calcium phosphate to act as a matrix for release. However, given the high water permeability of these cements the agents tend to be released in a short time (burst release), as observed in Fig. 9 with and without the use of mannitol as the pore former. Interestingly addition of porogens that dissolve rapidly (such as mannitol) increases the rate of release (Fig. 9). Using PLGA microspheres to control the release not only appears to increase the duration of release, but also allows for a tunable control of the release kinetics augmenting the attractive attributes of the composite cement $[29,30]$. These favorable results shown here does offer further opportunities for some of the features to be easily tuned which include, the polymer type, the molecular weight of the polymer used and the amount of polymer used in the cement; each of which allows us to modify the release kinetics of a specific agent. Herein we clearly demonstrate modifying the release rate of the model agent, vancomycin, by mixing it with the cement and the empty PLGA microspheres or by encapsulating it into the PLGA microspheres and mixing that with the cement (Fig. 9). These results suggest that we can further tune the release kinetics of agents as needed making the composite a viable treatment option for debilitating bone diseases

and traumatic injuries causing bone loss. For example, we could release vancomycin over 4-6 weeks using the former strategy and 10-12 weeks using the latter formulation. Further, the most significant advantage of using such polymer matrix-cement composites is that multiple agents can potentially be released at different, but desired, rates adding to the versatility and potency of the system.

\section{Conclusion}

The present study demonstrates the use of degradable PLGA microspheres along with calcium phosphate to form self-setting cements that convert into interconnecting macro-porous 
scaffolds after complete degradation of the PLGA. The sizes of the PLGA microspheres dictate the sizes of the macro-pores formed in the set cements and degradation products of the PLGA has a strong influence on the final composition of the set cements. The presence of macropores as well as formation of more soluble brushite phase in the final cement can have a pronounced effect on the degradation of the PLGA-ReCaPP composite cements. Moreover, the results of the present work also showed that a wide range of release profiles of the model agent, vancomycin, can be achieved from these composite cements and thus these composites could potentially serve as a controlled drugs eluting orthopedic-dental based regenerative scaffolds.

\section{Acknowledgements}

Authors would like to acknowledge the support of the Department of Bioengineering and the Department of Chemical and Petroleum Engineering at the University of Pittsburgh for use of equipment and facilities. Additionally, PNK would like to acknowledge the National Science Foundation (NSF-CBET - 0933153), the Edward R. Weidlein Chair Professorship funds as well as the Center for Complex Engineered Multifunctional Materials (CCEMM), Swanson School of Engineering, University of Pittsburgh for partial support and provision of equipment used for the present study.

\section{Appendix A. Supplementary data}

Electronic Supplementary Information (ESI) available: Preparation of PLGA microspheres. Preparation of cements powders. Table S1: Composition of the ReCaPP and PLGA-ReCaPP cement powders. Preparation of ReCaPP liquids. X-ray diffraction and Rietveld refinement analysis with HighScore Plus. Calcium concentration determination using Inductively Coupled Plasma. Figure S1. SEM images at different magnifications of ReCaPP cements after ageing 
under PBS at $37{ }^{\circ} \mathrm{C}$ for different time periods. Table S2. Percentage porosity assigned to different pore size intervals calculated using mercury intrusion volume and envelope density of the ReCaPP and PLGA-ReCaPP cement scaffolds. Table S3. Conversion of the ReCaPP and PLGA-ReCaPP cement scaffolds into HAp using Rietveld refinement analysis after incubating in PBS for different time points. The crystallite size of the HAp phase was calculated using Rietveld refinement and particle size was calculated from the BET measurement values.

\section{References}

[1] J.C. Reichert, S. Saifzadeh, M.E. Wullschleger, D.R. Epari, M.A. Schutz, G.N. Duda, H. Schell, M. van Griensven, H. Redl, D.W. Hutmacher, Biomaterials, 30 (2009) 2149-2163. [2] M. Bongio, J. van den Beucken, S.C.G. Leeuwenburgh, J.A. Jansen, J. Mater. Chem., 20 (2010) 8747-8759.

[3] H.G. Moghadam, G.K.B. Sandor, H.H.I. Holmes, C.M.L. Clokie, J. Oral Maxillofac. Surg., 62 (2004) 202-213.

[4] A. Sugawara, K. Asaoka, S.-J. Ding, Journal of Materials Chemistry B, 1 (2013) 1081-1089.

[5] M. Bohner, L. Galea, N. Doebelin, Journal of the European Ceramic Society, 32 (2012) 2663-2671.

[6] M. Bohner, Eur. Cells Mater., 20 (2010) 1-12.

[7] M. Bohner, U. Gbureck, J.E. Barralet, Biomaterials, 26 (2005) 6423-6429.

[8] S.V. Dorozhkin, Materials, 2 (2009) 221-291.

[9] S. Larsson, J. Orthop. Trauma, 24 (2010) S41-S45.

[10] E.M. Ooms, J.G.C. Wolke, J. van der Waerden, J.A. Jansen, J. Biomed. Mater. Res., 61 (2002) 9-18.

[11] M.P. Ginebra, T. Traykova, J.A. Planell, J. Control. Release, 113 (2006) 102-110.

[12] M.P. Ginebra, C. Canal, M. Espanol, D. Pastorino, E.B. Montufar, Adv. Drug Deliv. Rev., 64 (2012) 1090-1110.

[13] S. Bose, S. Tarafder, Acta Biomater., 8 (2012) 1401-1421.

[14] V. Karageorgiou, D. Kaplan, Biomaterials, 26 (2005) 5474-5491.

[15] K.A. Hing, Int. J. Appl. Ceram. Technol., 2 (2005) 184-199.

[16] M. Bohner, Y. Loosli, G. Baroud, D. Lacroix, Acta Biomater., 7 (2011) 478-484.

[17] E. Chevalier, D. Chulia, C. Pouget, M. Viana, J. Pharm. Sci., 97 (2008) 1135-1154.

[18] M.P. Ginebra, M. Espanol, E.B. Montufar, R.A. Perez, G. Mestres, Acta Biomater., 6 (2010) 2863-2873.

[19] C.G. Simon, C.A. Khatri, S.A. Wight, F.W. Wang, J. Orthop. Res., 20 (2002) 473-482.

[20] D.P. Link, J. van den Dolder, W.J.F.M. Jurgens, J.G.C. Wolke, J.A. Jansen, Biomaterials, 27 (2006) 4941-4947. 
[21] W.J.E.M. Habraken, J.G.C. Wolke, A.G. Mikos, J.A. Jansen, Journal of Biomaterials Science-Polymer Edition, 17 (2006) 1057-1074.

[22] R.P. Felix Lanao, S.C.G. Leeuwenburgh, J.G.C. Wolke, J.A. Jansen, Acta Biomater., 7 (2011) 3459-3468.

[23] J.M. Anderson, M.S. Shive, Adv. Drug Deliv. Rev., 28 (1997) 5-24.

[24] K.A. Athanasiou, G.G. Niederauer, C.M. Agrawal, Biomaterials, 17 (1996) 93-102.

[25] P.Q. Ruhe, O.C. Boerman, F.G.M. Russel, P.H.M. Spauwen, A.G. Mikos, J.A. Jansen, J. Control. Release, 106 (2005) 162-171.

[26] Z. Fei, Y. Hu, D. Wu, H. Wu, R. Lu, J. Bai, H. Song, J. Mater. Sci.-Mater. Med., 19 (2008) 1109-1116.

[27] J. Schnieders, U. Gbureck, R. Thull, T. Kissel, Biomaterials, 27 (2006) 4239-4249.

[28] W. Habraken, J.G.C. Wolke, J.A. Jansen, Adv. Drug Deliv. Rev., 59 (2007) 234-248.

[29] S.N. Rothstein, W.J. Federspiel, S.R. Little, Biomaterials, 30 (2009) 1657-1664.

[30] S.N. Rothstein, S.R. Little, J. Mater. Chem., 21 (2011) 29-39.

[31] T.P. Richardson, M.C. Peters, A.B. Ennett, D.J. Mooney, Nat. Biotechnol., 19 (2001) 10291034.

[32] M.P. Ginebra, T. Traykova, J.A. Planell, Biomaterials, 27 (2006) 2171-2177.

[33] H.N. Liu, T.J. Webster, J. Biomed. Mater. Res. Part A, 93A (2010) 1180-1192.

[34] J. Schnieders, U. Gbureck, E. Vorndran, M. Schossig, T. Kissel, J. Biomed. Mater. Res. Part B, 99B (2011) 391-398.

[35] J.W.M. Hoekstra, J.L. Ma, A.S. Plachokova, E.M. Bronkhorst, M. Bohner, J.L. Pan, G.J. Meijer, J.A. Jansen, J. van den Beucken, Acta Biomater., 9 (2013) 7518-7526.

[36] M.A. Lopez-Heredia, K. Sariibrahimoglu, W. Yang, M. Bohner, D. Yamashita, A. Kunstar, A.A. van Apeldoorn, E.M. Bronkhorst, R.P.F. Lanao, S.C.G. Leeuwenburgh, K. Itatani, F. Yang, P. Salmon, J.G.C. Wolke, J.A. Jansen, Acta Biomater., 8 (2012) 404-414.

[37] P.N. Kumta, C.S. Sfeir, A. Roy, Patent Number: US 08945538, University of Pittsburgh-Of the Commonwealth System of Higher Education, 2015.

[38] D. Olton, J.H. Li, M.E. Wilson, T. Rogers, J. Close, L. Huang, P.N. Kumta, C. Sfeir, Biomaterials, 28 (2007) 1267-1279.

[39] D.Y.E. Olton, J.M. Close, C.S. Sfeir, P.N. Kumta, Biomaterials, 32 (2011) 7662-7670.

[40] R.P. del Real, J.G.C. Wolke, M. Vallet-Regi, J.A. Jansen, Biomaterials, 23 (2002) 36733680.

[41] A. Almirall, G. Larrecq, J.A. Delgado, S. Martinez, J.A. Planell, M.P. Ginebra, Biomaterials, 25 (2004) 3671-3680.

[42] M. Bohner, Biomaterials, 25 (2004) 741-749.

[43] K. Ishikawa, Y. Miyamoto, M. Takechi, Y. Ueyama, K. Suzuki, M. Nagayama, T. Matsumura, J. Biomed. Mater. Res., 44 (1999) 322-329.

[44] I. Rehman, W. Bonfield, J. Mater. Sci.-Mater. Med., 8 (1997) 1-4.

[45] L. Tortet, J.R. Gavarri, G. Nihoul, A.J. Dianoux, J. Solid State Chem., 132 (1997) 6-16.

[46] S.M. Arifuzzaman, S. Rohani, J. Cryst. Growth, 267 (2004) 624-634. 
[47] J.X. Lu, B. Flautre, K. Anselme, P. Hardouin, A. Gallur, M. Descamps, B. Thierry, J. Mater. Sci.-Mater. Med., 10 (1999) 111-120.

[48] B. Otsuki, M. Takemoto, S. Fujibayashi, M. Neo, T. Kokubo, T. Nakamura, Biomaterials, 27 (2006) 5892-5900.

[49] T.G. Park, Biomaterials, 16 (1995) 1123-1130.

[50] M.A. Tracy, K.L. Ward, L. Firouzabadian, Y. Wang, N. Dong, R. Qian, Y. Zhang, Biomaterials, 20 (1999) 1057-1062.

[51] R.P. Felix Lanao, S.C.G. Leeuwenburgh, J.G.C. Wolke, J.A. Jansen, Biomaterials, 32 (2011) 8839-8847.

[52] W.J.E.M. Habraken, J.G.C. Wolke, A.G. Mikos, J.A. Jansen, Journal of Biomaterials Science-Polymer Edition, 19 (2008) 1171-1188.

[53] J.A. Jansen, J.W.M. Vehof, P.Q. Ruhe, H. Kroeze-Deutman, Y. Kuboki, H. Takita, E.L. Hedberg, A.G. Mikos, J. Control. Release, 101 (2005) 127-136.

[54] S.M. Li, H. Garreau, M. Vert, J. Mater. Sci--Mater. Med., 1 (1990) 123-130.

[55] S.M. Li, H. Garreau, M. Vert, J. Mater. Sci.-Mater. Med., 1 (1990) 131-139.

[56] W. Habraken, H.B. Liao, Z. Zhang, J.G.C. Wolke, D.W. Grijpma, A.G. Mikos, J. Feijen, J.A. Jansen, Acta Biomater., 6 (2010) 2200-2211.

[57] S. Kirkpatrick, Rev. Mod. Phys., 45 (1973) 574-588. 